\title{
The Mars rover subsurface penetrating radar onboard China's Mars 2020 mission
}

\author{
Bin Zhou ${ }^{1,2 *}$, ShaoXiang Shen ${ }^{1,2}$, Wei Lu ${ }^{1,2}$, YuXi Li ${ }^{1,2}$, Qing Liu ${ }^{1,2}$, ChuanJun Tang ${ }^{1,2}$, ShiDong Li, ${ }^{1,2}$, and \\ GuangYou Fang ${ }^{1,2}$ \\ ${ }^{1}$ Aerospace Information Research Institute, Chinese Academy of Sciences, Beijing 100190, China; \\ ${ }^{2}$ Key Laboratory of Electromagnetic Radiation and Detection Technology, Chinese Academy of Sciences, Beijing 100190, China
}

Citation: Zhou, B., Shen, S. X., Lu, W., Li, Y. X., Liu, Q., Tang, C. J., Li, S. D., and Fang, G. Y. (2020). The Mars rover subsurface penetrating radar onboard China's Mars 2020 mission. Earth Planet. Phys., 4(4), 345-354. http://doi.org/10.26464/epp2020054

\begin{abstract}
China's Mars probe, named Tianwen-1, including an orbiter and a landing rover, will be launched during the July-August 2020 Mars launch windows. Selected to be among the rover payloads is a Subsurface Penetrating Radar module (RoSPR). The main scientific objective of the RoSPR is to characterize the thickness and sub-layer distribution of the Martian soil. The RoSPR consists of two channels. The low frequency channel of the RoSPR will penetrate the Martian soil to depths of 10 to $100 \mathrm{~m}$ with a resolution of a few meters. The higher frequency channel will penetrate to a depth of 3 to $10 \mathrm{~m}$ with a resolution of a few centimeters. This paper describes the design of the instrument and some results of field experiments.
\end{abstract}

Keywords: SPR; Mars; Rover; LFM; subsurface; China's Mars 2020

\section{Introduction}

China plans to launch its first independent Mars probe during the July-August 2020 Mars launch windows. The probe will release both an orbiter and a landing rover, which will explore the planet jointly. The main goals of the mission are to assess the planet's environment and to search for evidence of both current and past life on the planet. The Mars orbiter and rover will collect data on the Martian surface topography, soil characteristics, material composition, water ice, atmosphere, ionosphere field, and other matters of scientific interest.

Since 1960, there have been more than 40 probes launched to Mars from all over the world. In previous Mars missions, some rovers have successfully landed on the surface of Mars, equipped with instruments such as cameras and X-ray spectrometers, but without subsurface penetrating radar (Missions to Mars, 2020). Recently planned Mars rover missions have added subsurface penetrating radar to their payloads. The ESA's ExoMars Rover mission, whose scientific objectives are to search for evidence of past and present life on Mars and to characterize the nature of the shallow subsurface, includes a stepped-frequency Ground Penetrating Radar instrument named WISDOM (Water Ice Subsurface Deposit Observation on Mars) with an objective to explore the first $\sim 3 \mathrm{~m}$ of the soil with a vertical resolution of a few centimeters (Ciarletti et al., 2011). The NASA Perseverance (Mars 2020 Rover) mission will carry a Gated-FMCW SPR named RIMFAX (Radar Imager for

Correspondence to: B. Zhou, zhb@mail.ie.ac.cn Received 26 MAY 2020; Accepted 16 JUN 2020.

Accepted article online 28 JUL 2020.

C 2020 by Earth and Planetary Physics.
Mars' Subsurface Experiment) to image subsurface structure and provide information regarding subsurface composition (Hamran et al., 2015). The RIMFAX penetrates to a depth of more than $10 \mathrm{~m}$ depending on ground conditions.

Selected for the payloads of China's first independent Mars mission is a Rover-mounted Subsurface Penetrating Radar instrument (RoSPR); its main scientific objective is to characterize the thickness and sub-layer distribution of the Martian soil. The RoSPR has two radar channels, one of which operates in the frequency range 15 to $95 \mathrm{MHz}$, and the other in the range 0.45 to $2.15 \mathrm{GHz}$. The lower frequency channel is designed to penetrate Martian soil to depths of 10 to $100 \mathrm{~m}$ with a resolution of a few meters; the higher frequency channel will penetrate 3 to $10 \mathrm{~m}$ with a resolution of a few centimeters. Actual penetration depths will depend on the composition of Martian materials encountered by the rover.

This paper presents a description of the RoSPR system, including its electronic architecture and antenna design. Results of some experimental verification testing, based on the engineering qualification model, are also given.

\section{Scientific Objectives}

The principal goals of the RoSPR are to investigate the thickness of the upper Martian soil and the structure of potentially buried water-ice or dry ice, and to determine the depth distribution of the subsurface stratigraphy.

For certain targets, material properties, and depths, the amplitude of the signal received by the Subsurface Penetrating Radar (SPR) decreases as the frequency increases. Thus, to achieve ad- 
equate penetrating depth in certain materials, the subsurface penetrating radar needs to have an operating frequency as low as possible. However, high resolution also requires a wide operating frequency bandwidth. Given the China mission's objectives, the design of our RoSPR, unlike that of the WISDOM or RIMFAX radars, incorporates a compromise between penetration and resolution. The China mission RoSPR's design incorporates two operating frequency channels to allow acquisition of useful data from both near surface and subsurface materials. Depending on the materials encountered, the lower frequency channel will be able to survey the subsurface stratigraphy to depths of 10 to $100 \mathrm{~m}$ with resolution of a few meters, while the higher frequency channel will be able to survey the structure of the near-surface Martian soil, 3

Table 1. The main characteristics of the RoSPR.

\begin{tabular}{lcc}
\hline \multirow{2}{*}{ Parameter } & \multicolumn{2}{c}{ Nominal values } \\
\cline { 2 - 3 } $\begin{array}{l}\text { LFM signal frequency } \\
\text { range }\end{array}$ & 15 to $95 \mathrm{MHz}$ & 0.45 to $2.15 \mathrm{GHz}$ \\
\hline Antenna polarization & $\mathrm{HH}$ & $\mathrm{HH}, \mathrm{HV}, \mathrm{VH}, \mathrm{VV}$ \\
\hline Depth resolution & $\mathrm{A}$ few meters & A few centimeters \\
\hline Depth range & $100 \mathrm{~m}$ (ice) & $10 \mathrm{~m}$ (ice) \\
\hline Weight & $10 \mathrm{~m}$ (soil) & $3 \mathrm{~m}$ (soil) \\
\hline Power consumption & \multicolumn{2}{c}{$6.1 \mathrm{~kg}$} \\
\hline
\end{tabular}

to $10 \mathrm{~m}$, with resolution of just a few centimeters. Table 1 presents the main characteristics of the two-channel RoSPR.

\section{Design of the Radar System}

In order to realize the mission's scientific objectives, the radar system has two channels, one in the frequency band $15-95 \mathrm{MHz}$ with depth resolution of several meters, for exploration of the subsur- face of Mars, and another channel operating in the frequency band $0.45-2.15 \mathrm{GHz}$ with depth resolution of about several centimeters, for determining in detail the composition of surface materials. Compared to the moon, the atmosphere of Mars is quite condensed. In the moon's atmosphere there are only $\sim 10^{4}$ molecules per cubic centimeter during the lunar day (Vaniman et al., 1991) and the atmospheric pressure on the moon is normally $10^{-10} \mathrm{~Pa}$, effectively a vacuum. The atmospheric pressure at the surface of Mars, measured at the two Viking sites, was found to vary over a Martian year from 0.7 to $1 \mathrm{kPa}$, which is no more than 1 percent of Earth's sea-level atmospheric pressure (Zubrin and Wagner, 1996). It is easy to produce low-pressure discharge in this range of atmospheric pressure when an instrument's working voltage is relatively high. Unlike the CE-3/4 Lunar Penetrating Radar (LPR), which is an impulsive subsurface penetrating radar (Fang GY et al., 2014) that uses avalanche transistors whose operating voltage is about 300 volt to produce impulse transmitting signals of hundreds of volts, the RoSPR adopts a linear frequency modulated signal as its transmitted signal, to avoid the use of high working voltages. The radar transmitted signal is a kind of linear frequency modulation (LFM) signal. The normalized complex transmitted signal has the form

$$
s(t)=\exp \left(\mathrm{j} 2 \pi\left(f_{c} t+\frac{\mu}{2} t^{2}\right)\right), \quad-\frac{T_{p}}{2} \leq t \leq \frac{T_{p}}{2},
$$

where $f_{c}$ is the center frequency, $\mu=B / T_{p}, B$ is the signal bandwidth, and $T_{p}$ is the pulse width. The transmitted signal is just the real part of $s(t)$. Figure 1 shows the transmitted signal waveform and the synthetic impulse after pulse compression. The values of $B$ and $T_{p}$ are $80 \mathrm{MHz}$ and $145 \mu \mathrm{s}$, respectively, for the lower frequency channel $(\mathrm{CH} 1)$, and $1.7 \mathrm{GHz}$ and $4 \mathrm{~ms}$, respectively, for the higher frequency channel $(\mathrm{CH} 2)$.

Physically, the radar unit consists of an electronic box, two lower frequency channel antennas, two higher frequency channel antennas, and six RF (Radio Frequency) coaxial cables. The radar's
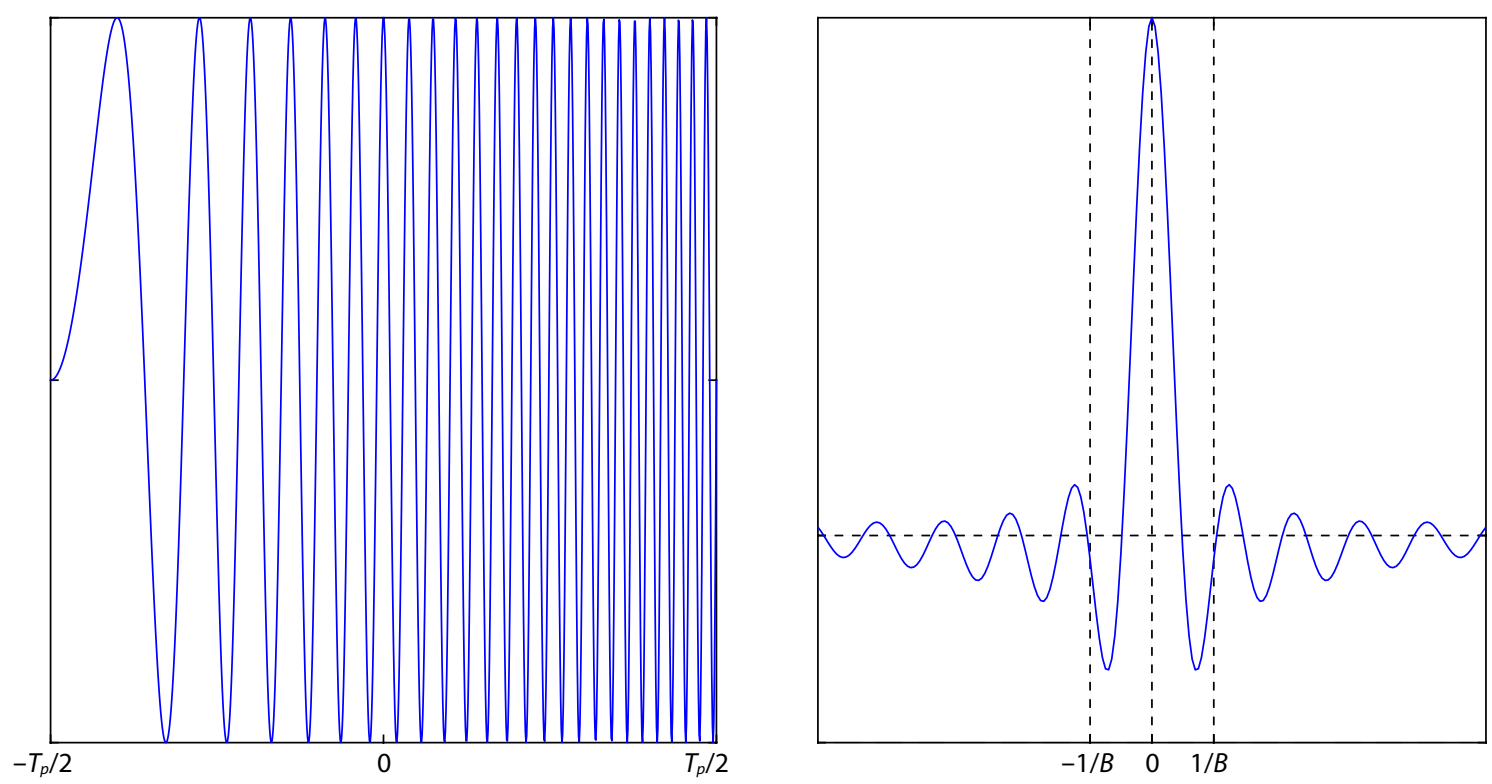

Figure 1. Waveform of the radar transmitting signal (left) and the synthetic impulse signal after pulse compression (right). 

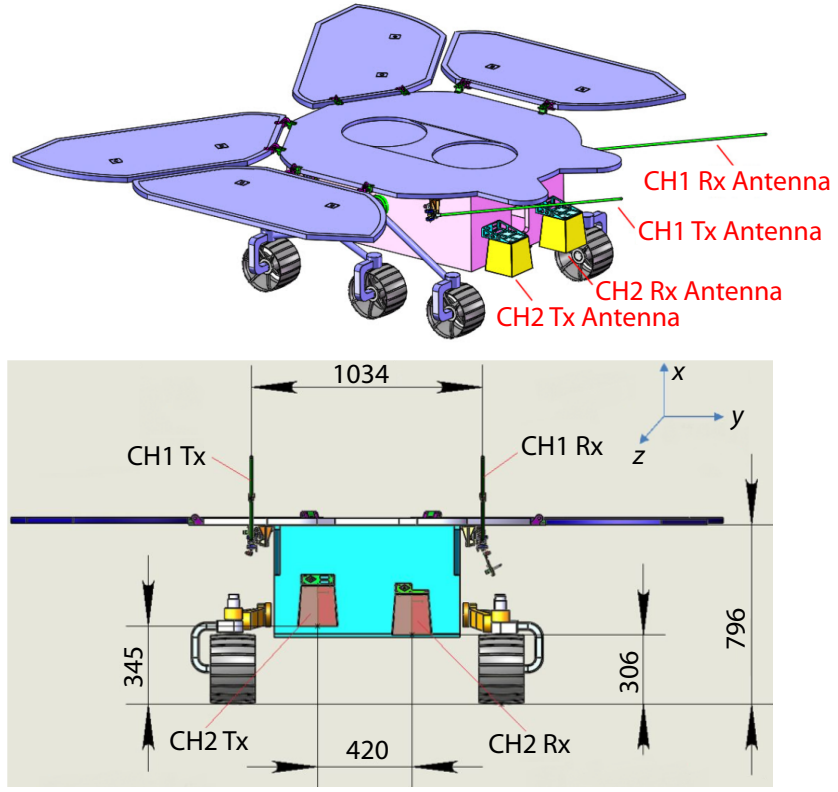

Figure 2. Positions of the RoSPR antennas on the rover.

electronic box is mounted in the cabin of the rover, and is powered by and communicates with the payload controller. The two $\mathrm{CH} 1$ antennas are mounted on two sides of the bottom surface of the rover's top board. The two $\mathrm{CH} 2$ antennas are mounted on the front board of the rover, as shown in Figure 2. In order to ensure the rover's ability to overcome obstacles, the antennas are installed with an upward angle of 16 degrees.

\subsection{The Radar Electronic Unit}

The radar's electronic unit is divided into several modules according to function. These modules are shown in Figure 3.

(1) Radar controller. Communicates with payload management unit, receiving instructions and transmitting data. Generates two- channel baseband chirp signals directly, using ADC (Analog to Digital Converter). Converts echo signals from the two channels from analog to digital; generates various controlling signals used by receivers and transmitters according to the operating mode, which is selected by a command received from the payload management unit through the communication bus interface.

(2) Master clock. Generates stable clock signals used in the radar controller and the radio frequency chirp signal generator.

(3) RF chirp signal generator. Generates the radio frequency chirp signal from the baseband chirp signal of the higher frequency channel mixing with the $4 \mathrm{GHz}$ signal.

(4) Transmitter. Amplifies the signal to the transmitting antenna. The higher frequency channel transmitter includes gating and a polarization selecting function.

(5) Receiver. Amplifies the echo signal received from the receiving antenna. The higher frequency channel receiver includes a gating function, a polarization selection, and converts RF signal to intermediate frequency (IF) band signal by using a mixer.

(6) IF processing module. Amplifies and filters the IF signals.

(7) Power supply module. Generates the various voltages used for the other circuit modules.

After the radar is powered on, the radar working parameters and working instructions are injected through the payload management unit (PMU). The two channels of the radar capture data at every preset distance interval and transfer the data to the PMU. The radar stops capturing data after receiving the stop instruction.

The $\mathrm{CH} 1$ chirp signal is generated by the DAC (digital to analog converter) with a sampling frequency of $400 \mathrm{MHz}$ based on the waveform storage method. The pulse width of the produced chirp signal from 15 to $95 \mathrm{MHz}$ is $145 \mu \mathrm{s}$. The pulse repetition frequency is $200 \mathrm{~Hz}$.

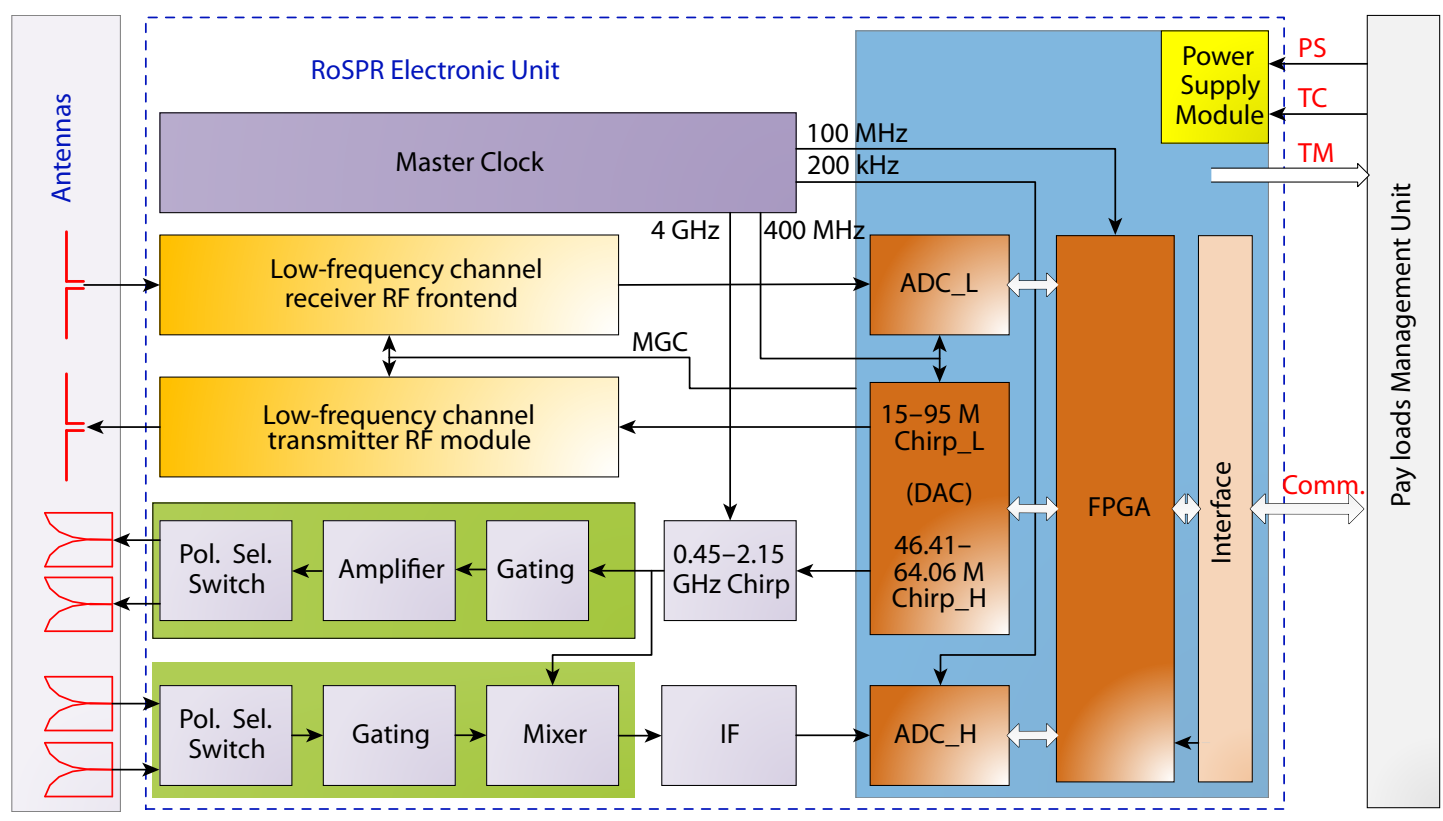

Figure 3. The RoSPR system composition and principle block diagram. 


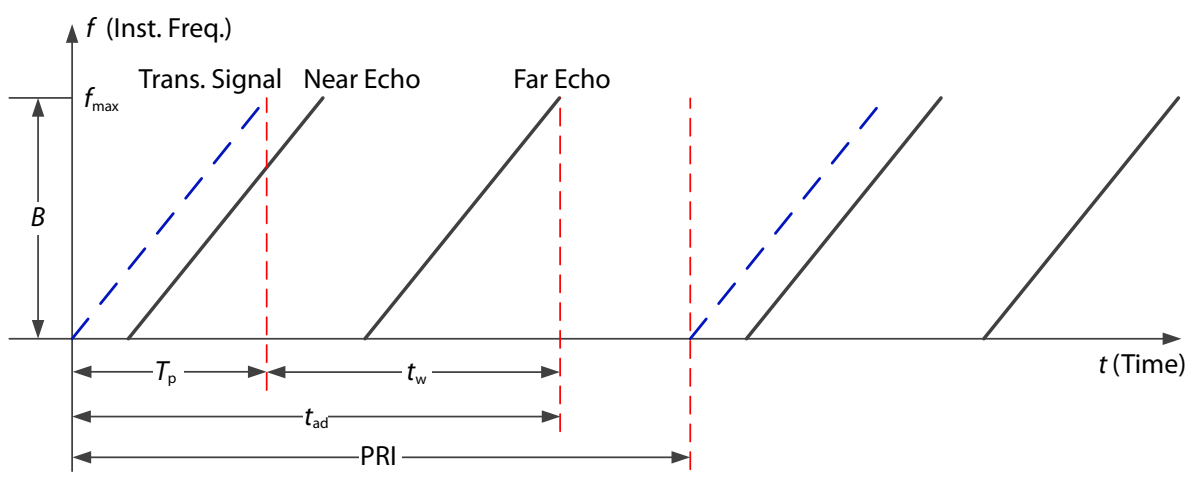

Figure 4. The operating timing of the $\mathrm{CH} 1$ radar.

The operating timing of the lower frequency channel radar is shown in Figure 4. The receiver works in all the times shown as $t_{\mathrm{ad}}$ in Figure 4 without a detection blind zone. A 14-bit high speed

Table 2. The $\mathrm{CH} 1$ radar design parameters.

\begin{tabular}{lcc}
\hline \multicolumn{1}{c}{ Parameter } & Value & Comment \\
\hline Frequency range & 15 to $95 \mathrm{MHz}$ & \\
Pulse width $\left(T_{p}\right)$ & $145 \mu \mathrm{s}$ & \\
PRI & $5 \mathrm{~ms}$ & \\
Penetrating time window & $t_{\mathrm{w}}: 5 \mu \mathrm{s}, 10 \mu \mathrm{s}, 15 \mu \mathrm{s}$ & \\
Maximum depth window & $375 \mathrm{~m}, 750 \mathrm{~m}, 1125 \mathrm{~m}$ & When $\varepsilon_{r}=4$ \\
Transmitted power & $+27 \mathrm{dBm}$ & \\
Receiving sensitivity & $-87 \mathrm{dBm}$ & \\
\hline
\end{tabular}

$A D C$ is used in the analog to digital conversion of the echo signal. Table 2 summarizes the main design parameters of the $\mathrm{CH} 1$ radar.

The $\mathrm{CH} 2$ baseband chirp signal is generated by the DAC at a sampling frequency of $400 \mathrm{MHz}$ using a direct digital frequency synthesizer. The pulse width of the produced chirp signal from 46.4167 MHz to $64.0625 \mathrm{MHz}$ is $4 \mathrm{~ms}$. The pulse repetition fre- quency is $200 \mathrm{~Hz}$. The baseband chirp signal is multiplied by 96 using a VCO (Voltage Controlled Oscillator) and PLL (Phase Locked Loop). The RF chirp signal from 0.45 to $2.15 \mathrm{GHz}$ is generated after mixing the multiplied signal from 4.45 to $6.15 \mathrm{GHz}$ with a $4 \mathrm{GHz}$ local oscillating signal.

The operating timing of the higher frequency channel radar is shown in Figure 5. The receiver receives the echo from the start to the stop of the transmitting signal, shown as $t_{\mathrm{ad}}$ in Figure 5. A 16bit ADC will be used in the analog to digital conversion of IF signal. Table 3 summarizes the $\mathrm{CH} 2$ radar main design parameters.

\subsection{The Antennas}

The ultra-wideband antenna system is one of the most critical parts of the RoSPR system. The design requirements of the antenna system are mainly driven by scientific objectives of the exploration and considerations of feasible volume, weight, and installation position on the rover.

As shown in Figure 2, the two $\mathrm{CH} 1$ antennas are mounted on two sides of the bottom surface of the rover's top board. The $\mathrm{CH} 2$ antennas are mounted on the front board of the Mars rover, and their main direction for radiation is toward the Martian surface.

The $\mathrm{CH} 1$ antennas' design is inherited from the $\mathrm{CH} 1$ antennas of

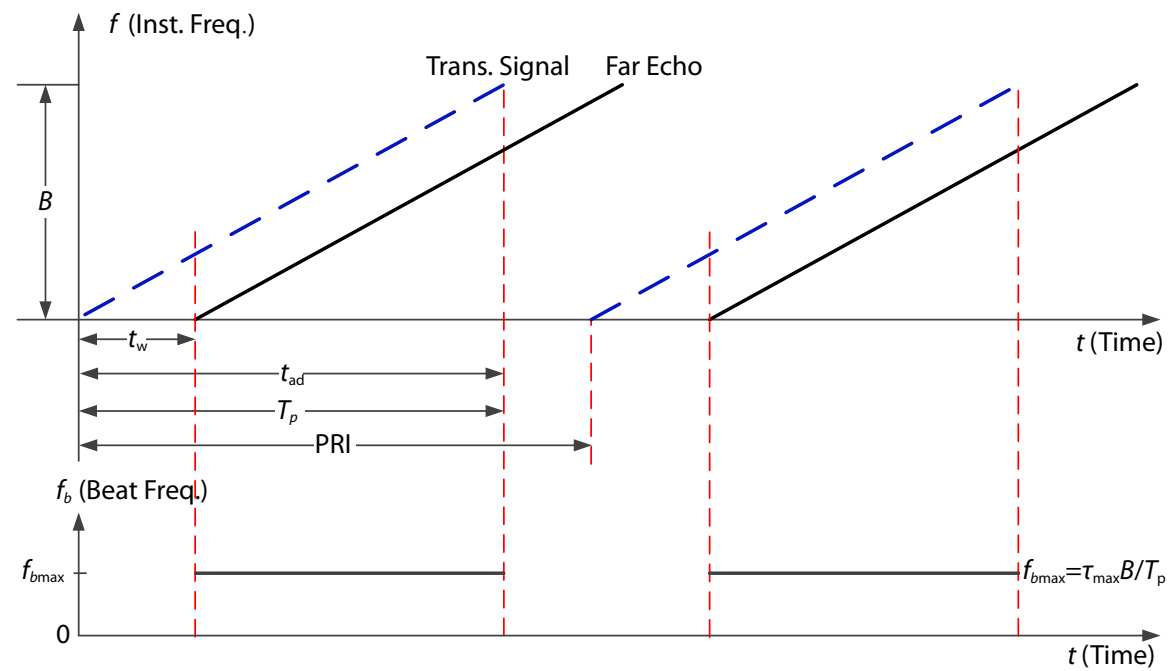

Figure 5. The operating timing of the $\mathrm{CH} 2$ radar. 
Table 3. The $\mathrm{CH} 2$ radar design parameters.

\begin{tabular}{lcc}
\hline \multicolumn{1}{c}{ Parameter } & Value & Comment \\
\hline Frequency band & $0.45 \mathrm{to}$ & \\
& $2.15 \mathrm{GHz}$ & \\
Pulse width $\left(T_{p}\right)$ & $4 \mathrm{~ms}$ & \\
PRI & $5 \mathrm{~ms}$ & \\
Penetrating time & $t_{\mathrm{w}}: 235 \mathrm{~ns} \quad$ IF sampling frequency is 200 \\
window & $17.6 \mathrm{~m}$ & $\mathrm{kHz}$ \\
Maximum depth & When $\varepsilon_{r}=4$ \\
window & $+27 \mathrm{dBm}$ & \\
Transmitted power & $-120 \mathrm{dBm}$ & \\
Receiving sensitivity & &
\end{tabular}

the LPR onboard the Chang'e-3 Mission (Fang GY et al., 2014). The structure of $\mathrm{CH} 1$ antennas is shown as Figure 6. Each $\mathrm{CH} 1$ monopole antennas is mounted in a tubular radome, which protects and supports the antenna. The radome is $1350 \mathrm{~mm}$ in length and $12 \mathrm{~mm}$ in diameter. The transmitting and receiving antennas are spaced about $1034 \mathrm{~mm}$ apart. In order to expand the bandwidth of the antenna, the Wu-King impedance loading method ( $\mathrm{Wu} T$ and King, 1965) is used to provide a continuous resistive load from the feed point to the end of the antenna. Actually, a continuous distribution of the resistance load is generally difficult to produce, so a piecewise loading method is usually used, namely "con- centrated resistive loading".

Figure 7 shows the simulated VSWR characteristics and gain characteristic of the $\mathrm{CH} 1$ antenna. The VSWR is less than 3 in the frequency band 35 to $75 \mathrm{MHz}$.

The $\mathrm{CH} 2$ antennas consist of two perpendicular transmitting antenna elements and two perpendicular receiving antenna elements. The structure of the $\mathrm{CH} 2$ antennas is shown as Figure 8. The antenna is based on Vivaldi design (Gibson, 1979) and its envelope size is $280 \mathrm{~mm} \times 230 \mathrm{~mm} \times 205 \mathrm{~mm}$. The height of the Vivaldi antenna element is $170 \mathrm{~mm}$. The simulated VSWR characteristic and gain characteristic of the $\mathrm{CH} 2$ antenna are shown in Figure 9. The VSWR is less than 2 in the frequency band 0.8 to $1.8 \mathrm{GHz}$.

\section{Data Format}

The low frequency channel radar is an LFM radar with $145 \mu \mathrm{s}$ transmitting signal pulse width. The synthetic response in time domain is obtained by convolution of the receiving data with the transmitting chirp.

The high frequency channel radar is a LFM radar with $4 \mathrm{~ms}$ transmitting signal pulse width. The synthetic response in time domain is obtained by Fourier transform performed on the IF signal data, which is generated by the receiving signal mixed with the replication of the transmitting signal. (a)

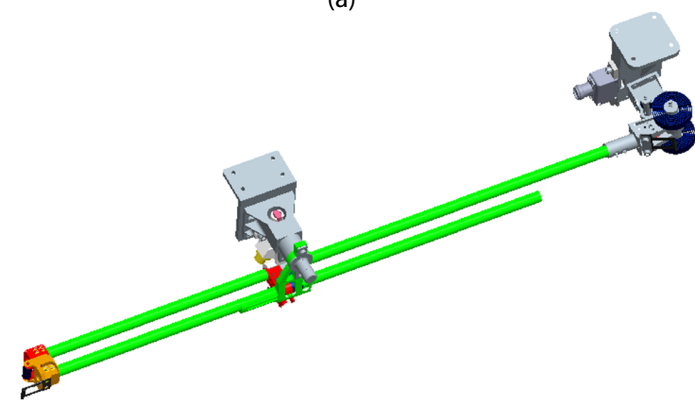

(b)

Figure 6. The structure of the $\mathrm{CH} 1$ antenna. (a) Folded status; (b) Unfolded status.
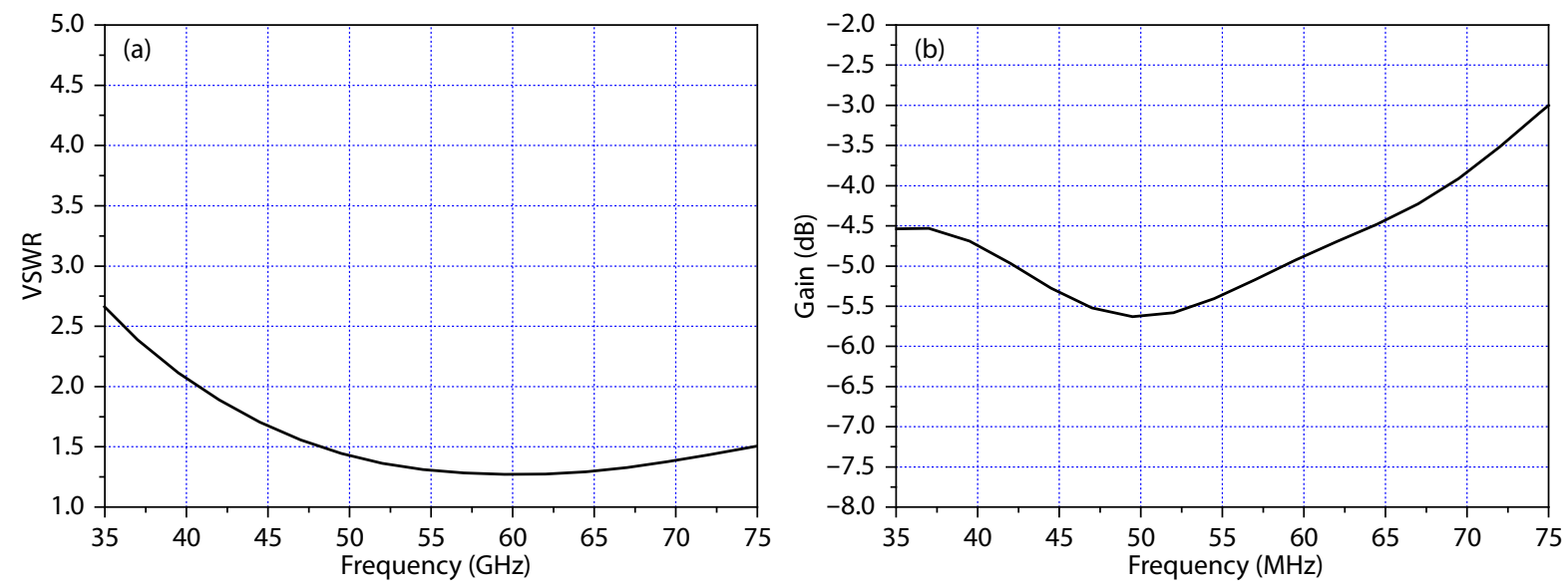

Figure 7. VSWR and Gain of the $\mathrm{CH} 1$ antenna. (a) VSWR; (b) Gain. 

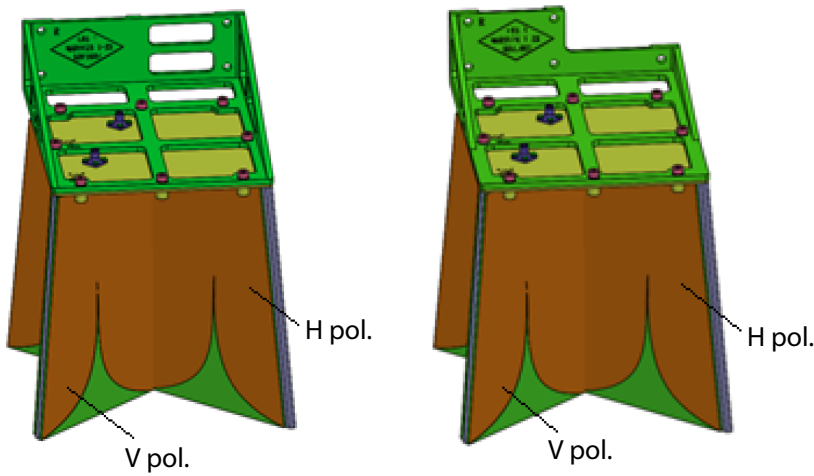

Figure 8. The structure of the $\mathrm{CH} 1$ transmitting (left) and receiving (right) antennas.
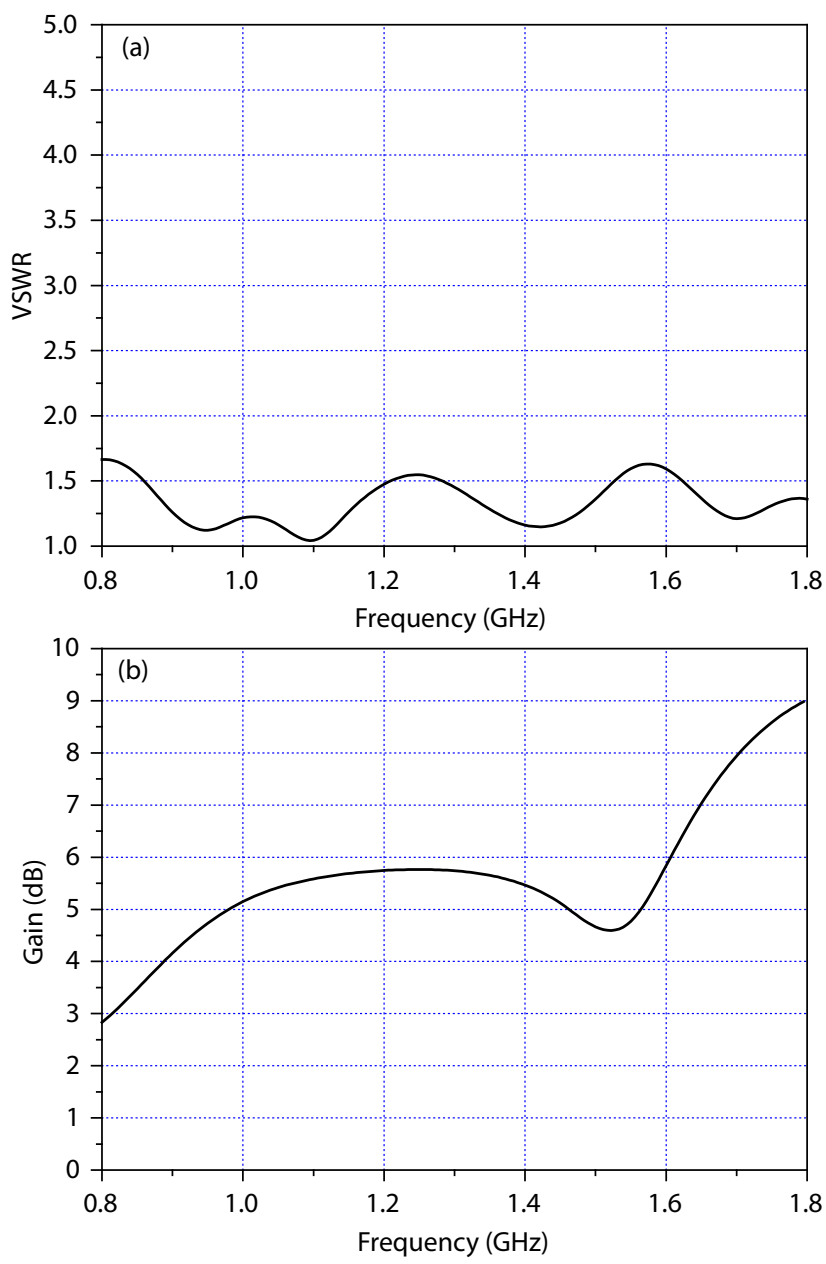

Figure 9. VSWR and Gain of the $\mathrm{CH} 2$ antenna. (a) VSWR; (b) Gain.

Because of the large quantity of raw data from the low frequency channel radar trace, data compression is adopted in order to facilitate efficient transmission of exploration findings from Mars to Earth.

Table 4 shows the data frame format of the RoSPR. The data type of the low-frequency channel includes: the real part of the pulse compression data, the real and imaginary parts of the pulse compression data, and the compressed version of these data. The data
Table 4. The definition of the radar data.

\begin{tabular}{|c|c|c|c|}
\hline Item & Para. Name & Bytes & Description \\
\hline 1 & Channel mark & 4 & $\begin{array}{l}\mathrm{CH} 1: 0 \times 146 \mathrm{~F} 1111 \\
\mathrm{CH} 2: 0 \times 146 \mathrm{~F} 2222\end{array}$ \\
\hline \multirow{6}{*}{2} & \multirow{6}{*}{$\begin{array}{c}\text { Data type } \\
\text { identification }\end{array}$} & 1 & $\begin{array}{l}\text { Sign of the data format } \\
\text { 0xA8: } \mathrm{CH} 2-\mathrm{HH} \text { raw data } \\
\text { 0xA9: } \mathrm{CH} 2-\mathrm{HV} \text { raw data } \\
\text { OxAA: } \mathrm{CH} 2-\mathrm{VH} \text { raw data } \\
\text { 0xAB: } \mathrm{CH} 2-\mathrm{VV} \text { raw data } \\
\text { 0xE8: } \mathrm{CH} 2-\mathrm{HH} \text { real and } \\
\text { imaginary parts } \\
\text { 0xE9: } \mathrm{CH} 2-\mathrm{HV} \text { real and } \\
\text { imaginary parts } \\
\text { 0xEA: } \mathrm{CH} 2-\mathrm{VH} \text { real and } \\
\text { imaginary parts } \\
\text { 0xEB: } \mathrm{CH} 2-\mathrm{VV} \text { real and } \\
\text { imaginary parts } \\
\text { 0xBB: } \mathrm{CH} 1 \text { real part } \\
\text { 0xCC: } \mathrm{CH} 1 \text { real and } \\
\text { imaginary parts }\end{array}$ \\
\hline & & 1 & $\begin{array}{l}\text { Data compression ratio of } \\
\quad \text { CH1 } \\
\text { 0x00: no compression } \\
\text { OxOF: } 2.5: 1 \\
\text { OxF0: } 4: 1\end{array}$ \\
\hline & & 1 & $\begin{array}{l}\text { Time window of } \mathrm{CH} 1 \\
\text { 0xAA : } 15 \mu \mathrm{s} \\
\text { 0xBB : } 10 \mu \mathrm{s} \\
\text { 0xCC: } 5 \mu \mathrm{s} \\
\text { 0xDD: } 2.5 \mu \mathrm{s}\end{array}$ \\
\hline & & 1 & Firmware version \\
\hline & & 1 & $\begin{array}{l}\text { Data compression ratio of } \\
\quad \mathrm{CH} 2 \\
\text { 0x00: no compression } \\
\text { 0x0F: } 2.5: 1 \\
\text { 0xF0: } 4: 1\end{array}$ \\
\hline & & 1 & Reserved \\
\hline 3 & Velocity & 6 & S0-S3 \\
\hline 4 & Reserved & 12 & Reserved \\
\hline \multirow[t]{2}{*}{5} & \multirow[t]{2}{*}{ Posture } & \multirow[t]{2}{*}{12} & $\begin{array}{l}\text { Pitching: } 2 \text { bytes } \\
\text { Yawing: } 2 \text { bytes } \\
\text { Rolling: } 2 \text { bytes }\end{array}$ \\
\hline & & & 6 bytes reserved \\
\hline 6 & Trace para. & 28 & $\begin{array}{l}\text { The working parameter of } \\
\text { the radar }\end{array}$ \\
\hline 7 & $\begin{array}{l}\text { Length of the } \\
\text { data set }\end{array}$ & 2 & \multirow[t]{2}{*}{ Shown as Table 5, Table 6} \\
\hline 8 & Data set & $\mathrm{N}$ & \\
\hline
\end{tabular}

sampling time interval of the low-frequency channel is $10 \mathrm{~ns}$. The data type of the high-frequency channel includes: the raw data, the real and imaginary parts of the pulse compression data, and the compressed version of the pulse compression data. The raw data sampling frequency of the high-frequency channel is $200 \mathrm{kHz}$. The data volumes of the two RoSPR channels are shown as Table 5 and Table 6. 
Table 5. The data volume of the low-frequency channel.

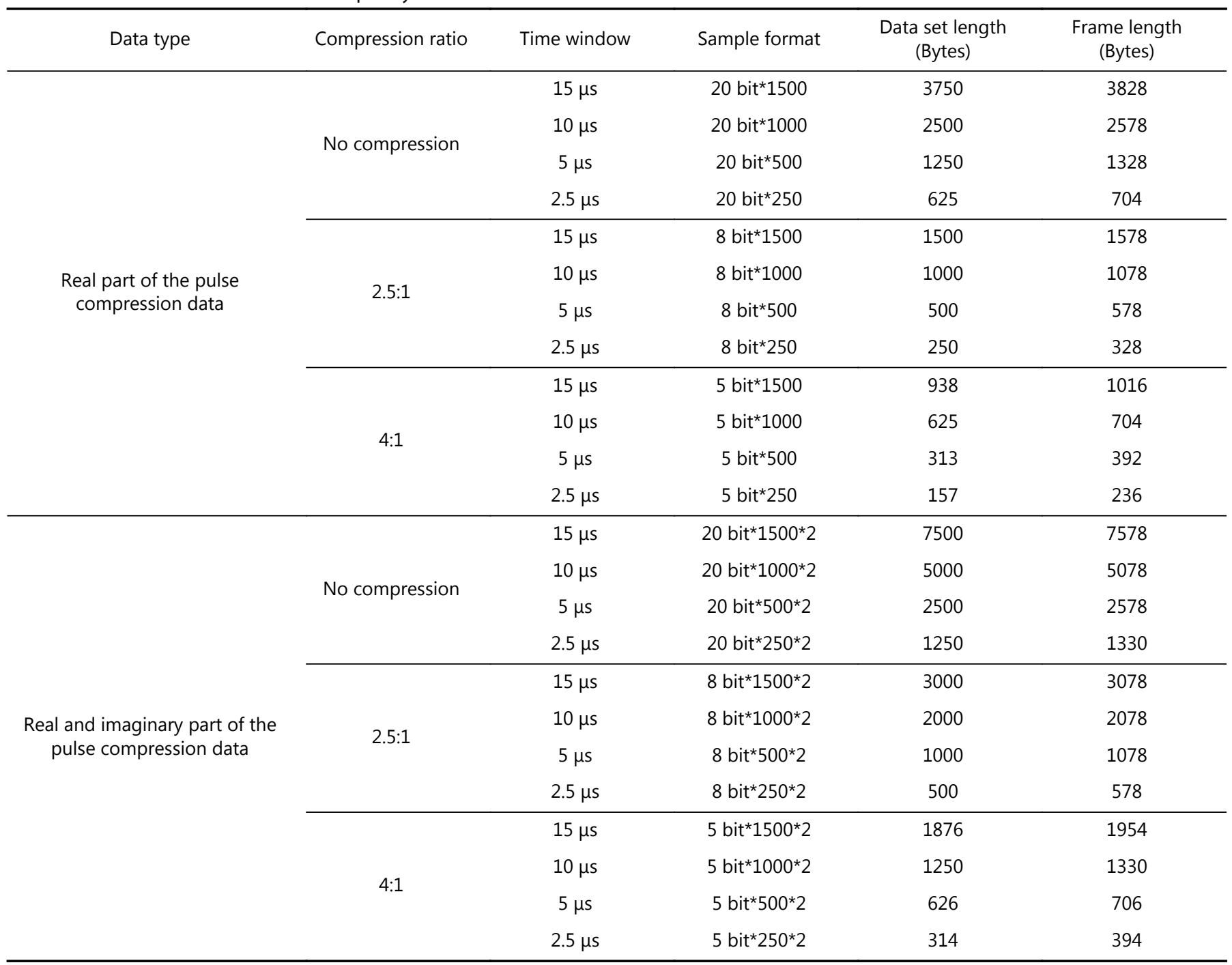

Table 6. The data volume of the high-frequency channel.

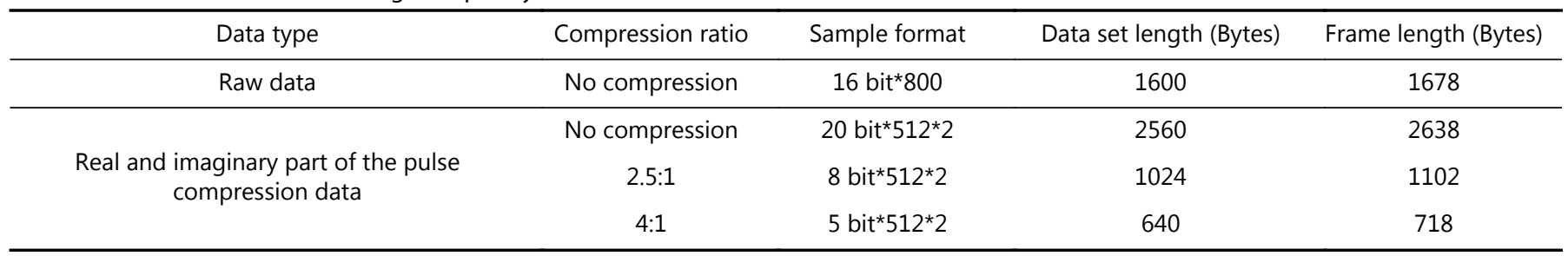

\section{Results}

Some performance tests with the engineering qualified model were performed in the laboratory test bench. Through the loopback test, in which the transmitting signal is attenuated by $20 \mathrm{~dB}$ and fed directly into the receiver through a coaxial cable, we can evaluate the performance of the radar's transmitter and receiver. Loopback test results for the two channels are shown in Figure 10 and Figure 11.

The initial laboratory field test performed in the indoor GPR testing ground was designed to verify the instrument's performance and evaluate the interaction between the radar and the rover. The experimental setup consists of a rover model and a test pool filled with artificial volcanic ash. The size of the pool is $7 \mathrm{~m}$ length, $3 \mathrm{~m}$ width, and $2.5 \mathrm{~m}$ height, shown as Figure 12. The measurement result of the relative permittivity of the filled material is 2.94 , with 0.56 uncertainty. Because the test space was too small for the low frequency channel radar, only the high frequency channel test was performed.

The engineering model radar, mounted on the rover model, was placed above the pool. Profile was obtained when the rover was lifted from $0 \mathrm{~m}$ height up to about $2.6 \mathrm{~m}$, then down to $0 \mathrm{~m}$ in about 6.5 minutes, as shown in Figure 13a. The data were processed by applying a background-removing algorithm. The processed data show that the reflection interfaces of the top and bottom of the pool are obviously distinguished, demonstrating that the high frequency channel radar is able to penetrate to more 

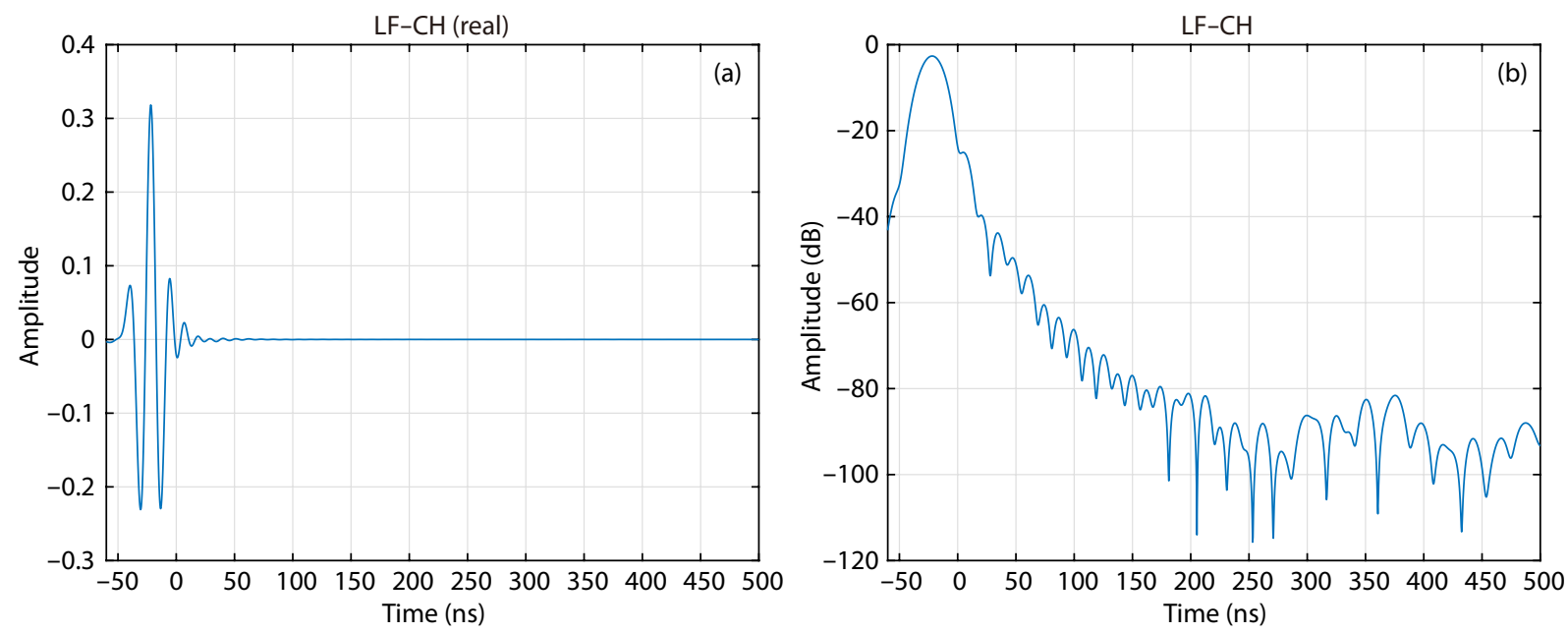

Figure 10. Results of the low frequency channel loopback test. (a) Real part of the synthetic response in the time domain. (b) Synthetic response in the time domain in decibels.
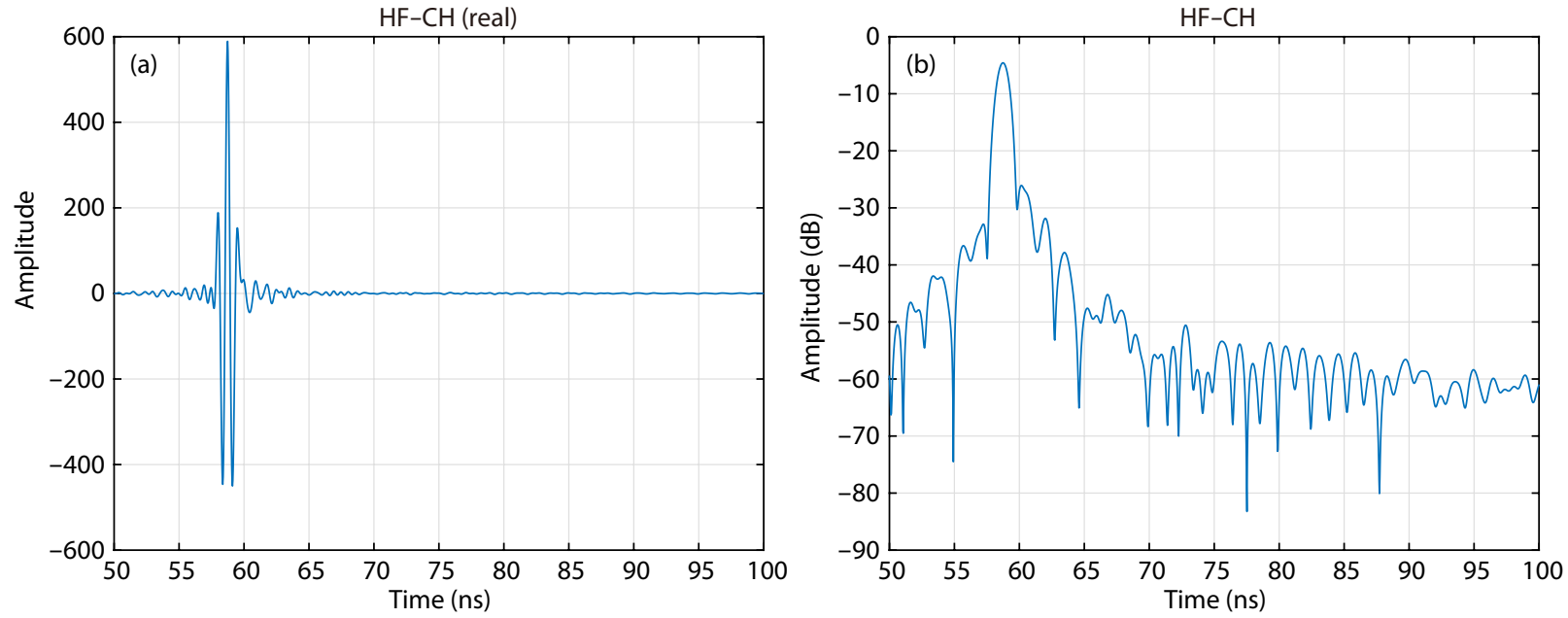

Figure 11. Results of the high frequency channel loopback test. (a) Real part of the synthetic response in the time domain. (b) Synthetic response in the time domain in decibels.

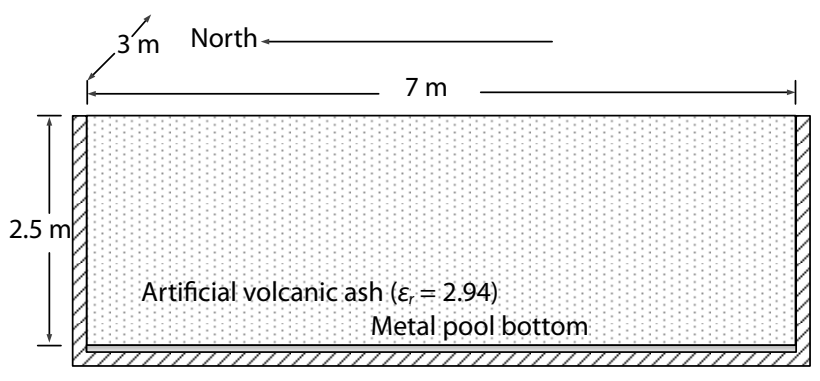

Figure 12. The test pool filled with artificial volcanic ash.

than $2.5 \mathrm{~m}$ in man-made volcanic ash, as shown in Figure $13 \mathrm{~b}$.

Another profile was obtained when the rover was moved from the north of the pool to the south, with a copper-clad plate laid obliquely in the pool, as shown in Figure 14a. The moving speed was the actual design speed of the Mars rover, about $200 \mathrm{~m}$ per hour. The processed profile shows that the test objects (the oblique copper clad plate and the metal pool bottom) can obviously be identified, as shown in Figure 14b.

Other field tests were performed in a parking lot and a volcano geo park. The parking lot test was intended only to verify that the $\mathrm{CH} 1$ radar had no blind zone; the rover carried the $\mathrm{Ch} 1$ radar in a straight line toward an automobile from far to near and back to far. The echo of the car can be seen in the radar profile, as shown in Figure 15b. The test in the geo park was intended mainly to verify the $\mathrm{CH} 2$ radar. Below the test line were layers of loose soil formed by volcanic eruption, as shown in Figure 16a. The dielectric constant of the soil is about 3 . The $\mathrm{CH} 2$ generated a radar profile along the test line. The echoes of the stratification can be seen in the profile, as shown in Figure 16b.

\section{Conclusions}

The RoSPR has been designed to meet the scientific requirements of the Tianwen-1 mission, China's first independent Mars exploration mission, which uses radar $\mathrm{CH} 1$ to investigate the Martian subsurface down to a depth of $\sim 10-100$ meters with a resolution of a 

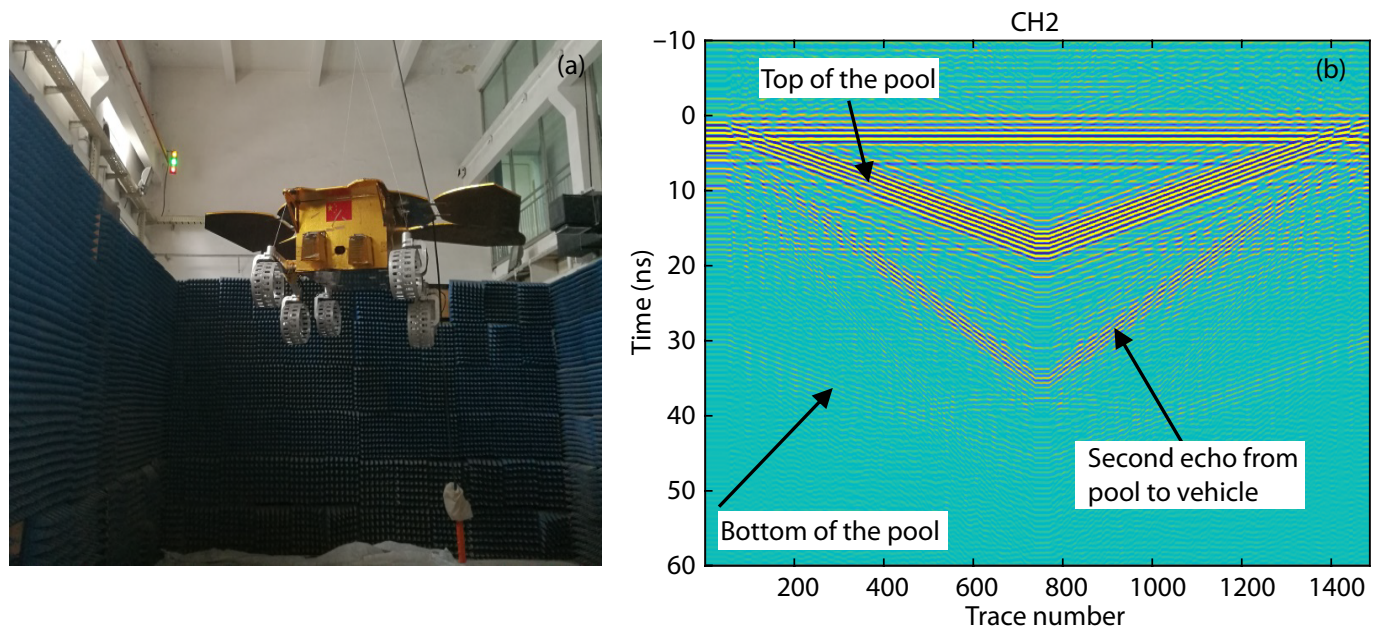

Figure 13. The profile obtained when the rover is lifted up and down. (a) The photo of the field test; (b) The radar profile.
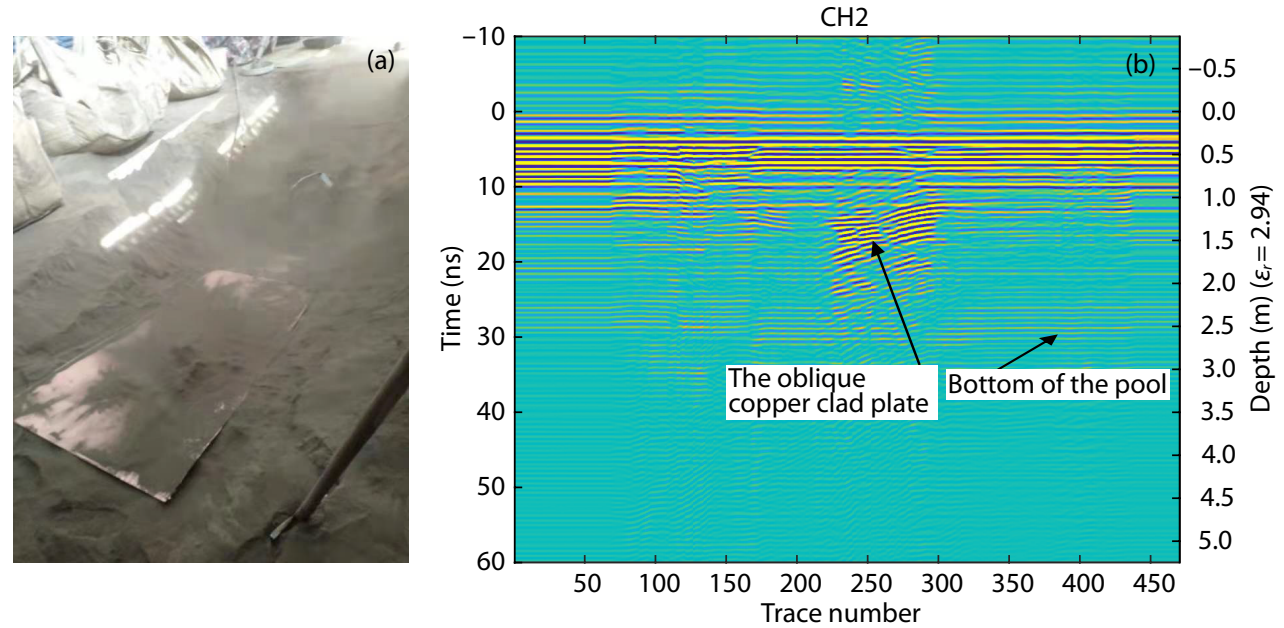

Figure 14. Test of radar as rover moved from north to south on pool top above oblique copper target plate. (a) Photo of the field test; (b) Radar profile obtained.
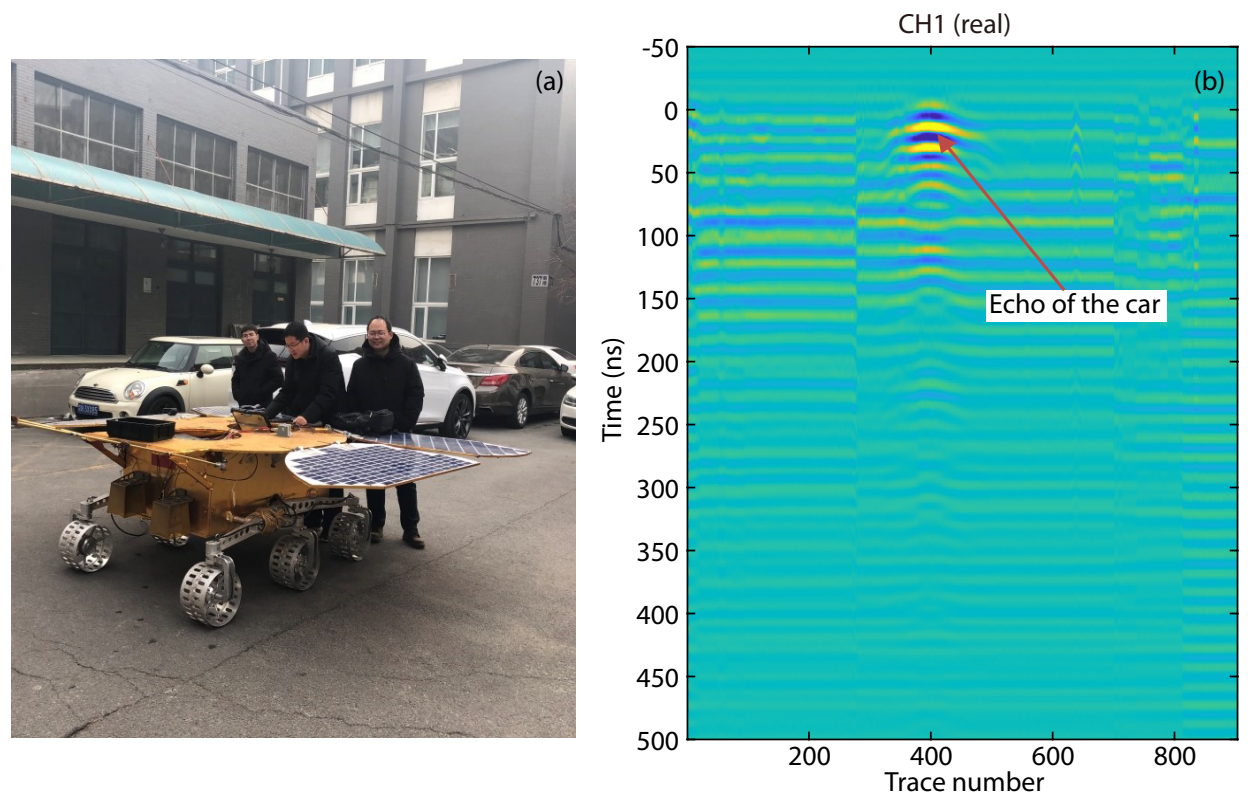

Figure 15. Parking lot test of the low-frequency channel's ability to obtain a radar profile. (a) Photo of the field test; (b) Radar profile generated from automobile target. 

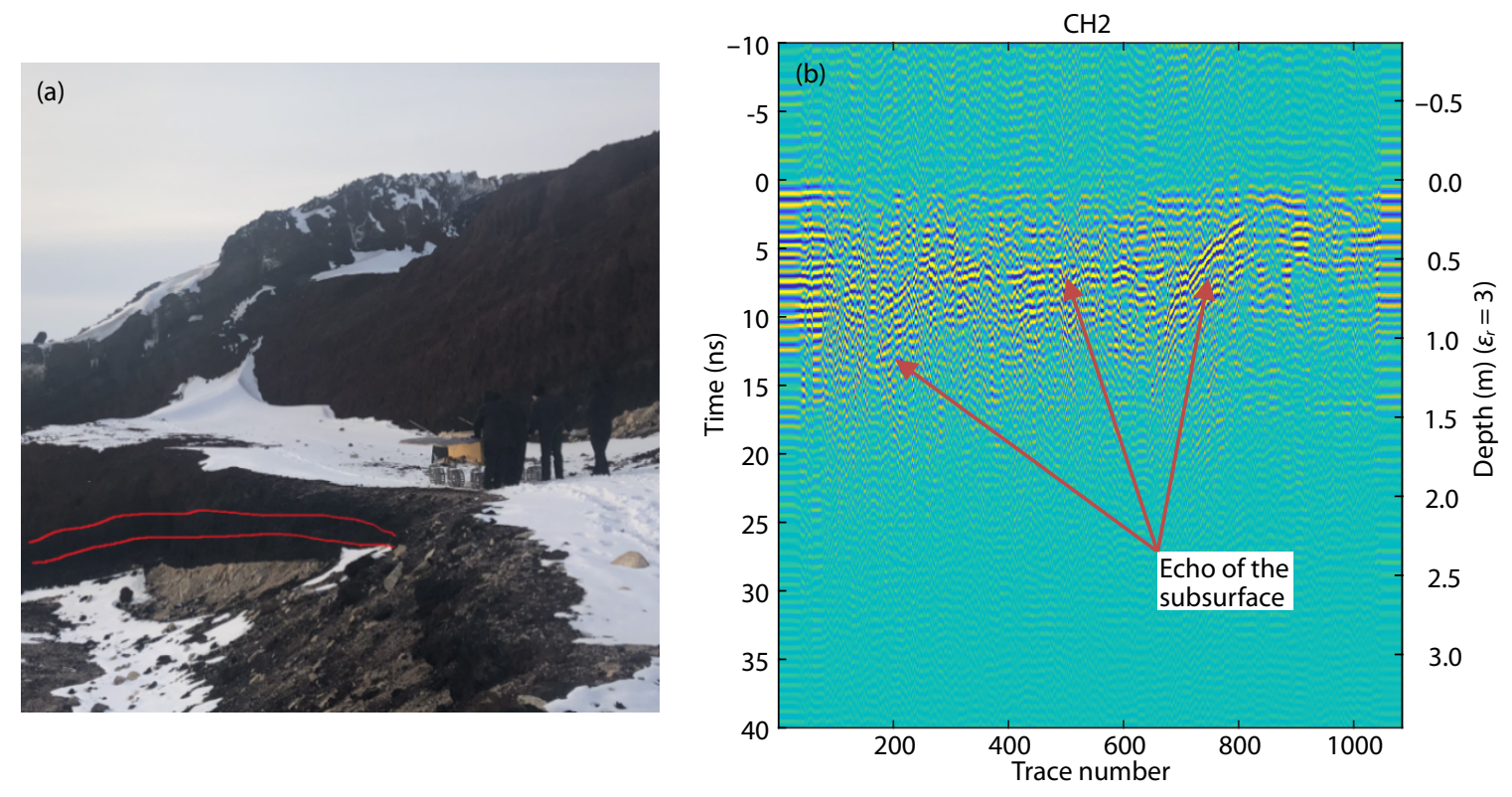

Figure 16. Volcano geopark test of the high-frequency channel radar. (a) Photo of the field test; (b) Radar profile of volcanic strata

few meters and radar $\mathrm{CH} 2$ tp investigate the Martian near-subsurface down to a depth of $\sim 3-10$ meters with a resolution of a few centimeters resolution.

Some tests were carried out using the engineering qualified model, whose technical conditions are equivalent to the final flight model.

The flight model of the radar has been assembled into the Tianwen-1 spacecraft, which will be launched from the Wenchang spaceport during the July-August 2020 Mars launch windows, and is expected to reach Mars around February 2021.

\section{Acknowledgments}

All the authors acknowledge support from the China National Space Administration. We thank the Ground Application System of Lunar and Deep Space Exploration, National Astronomical Observatories, Chinese Academy of Sciences, for their efficient help in the radar field verification experiment.

\section{References}

Ciarletti, V., Corbel, C., Plettemeier, D., Cais, P., Clifford, S. M., and Hamran, S. E.
(2011). WISDOM GPR designed for shallow and high-resolution sounding of the Martian subsurface. Proc. IEEE, 99(5), 824-836. https://doi.org/10.1109/JPROC.2010.2100790

Fang, G. Y., Zhou, B., Ji, Y. C., Zhang, Q. Y., Shen, S. X., Li, Y. X., Guan, H. F., Tang, C. J., Gao, Y. Z., ... Wang, S. Z. (2014). Lunar Penetrating Radar onboard the Chang'e-3 mission. Res. Astron. Astrophys., 14(12), 1607-1622. https://doi.org/10.1088/1674-4527/14/12/009

Gibson, P. J. (1979). The Vivaldi aerial. In 9th European Microwave Conference Proceedings (pp. 101-105). Brighton.

Hamran, S. E., Berger, T., Brovoll, S., Damsgård, L., Helleren, Ø., Øyan, M. J., Amundsen, H. E., Carter, L., Ghent, R., ... Eide, J. (2015). RIMFAX: A GPR for the Mars 2020 rover mission. In Proceedings of the 8th International Workshop on Advanced Ground Penetrating Radar (IWAGPR) (pp. 1-4). Florence: IEEE. https://doi.org/10.1109/IWAGPR.2015.7292690

Missions to Mars. (2020). website: https://www.planetary.org/explore/spacetopics//space-missions/missions-to-mars.html

Vaniman, D., Reedy, R., Heiken, G., Olheoft, G., and Mendell, W. (1991). The lunar environment. In G. Heiken, et al. (Eds.), Lunar Sourcebook (pp. 27-60). Cambridge: Cambridge University Press.

Wu, T., and King, R. (1965). The cylindrical antenna with nonreflecting resistive loading. IEEE Trans. Antennas Propag., 13(3), 369-373. https://doi.org/10.1109/TAP.1965.1138429

Zubrin, R., and Wagner, R. (1996). The Case for Mars: The Plan to Settle the Red Planet and Why We Must (pp. 147). New York: Touchstone. 